\title{
All cause mortality and its determinants in middle aged men in Finland, The Netherlands, and Italy in a 25 year follow up
}

A Menotti, A Keys, D Kromhout, A Nissinen, H Blackburn, F Fidanza, S Giampaoli, M Karvonen, J Pekkanen, S Punsar, F Seccareccia

Abstract

Study objective-The aims were (1) to compare all cause mortality in population samples of different cultures; and (2) to cross predict fatal event by risk functions involving risk factors usually measured in cardiovascular epidemiology.

Design-The study was a 25 year prospective cohort study. The prediction of all cause mortality was made using the multiple logistic equation as a function of 12 risk factors; the prediction of months lived after entry examination was made by the multiple linear regression using the same factors.

Population samples-There were five cohorts of men aged 40-59 years, from Finland (two cohorts, 1677 men), from The Netherlands (one cohort, $878 \mathrm{men}$ ), and from Italy (two cohorts, 1712 men).

Setting-The Finnish cohorts came from geographically defined rural areas, the Dutch cohort from a small town in central Holland, and the Italian cohorts from rural villages in northern and central Italy.

Measurements and main results-All cause mortality was highest in Finland (557 per 1000), and lower in The Netherlands (477) and in Italy (475). The solutions of the multiple logistic function showed the significant and almost universal predictive role of certain factors, with rare exceptions. These were age, blood pressure, cigarette smoking, and arm circumference (the latter with a negative relationship). Similar results were obtained when solving a multiple linear regression equation predicting the number of months lived after entry examination as a function of the same factors. The prediction of fatal events in each country, using the risk functions of the others, produced limited errors, the smallest one being $-2 \%$ and the largest $+11 \%$. When solving the logistic model in the pool of all the cohorts with the addition of dummy variables for the identification of nationality, it also appeared that only a small part of the mortality differences between countries is not explained by 12 available risk factors.

Conclusions-A small set of risk factors seems to explain the intercohort differences of 25 year all cause mortality in population samples of three rather different cultures.

Some of the major population studies originally designed to investigate coronary or cardiovascular diseases have recently reached very long term follow up stages, at least in the collection of mortality data. ${ }^{1-15}$ This means that the population samples have moved into geriatric ages and that a large number of fatal events are occurring with aging, year after year, at exponential rate.

In this situation it becomes more interesting to investigate all cause mortality as a reflection of the expectancy of life than to carry out deeper analyses on cardiovascular conditions or other single causes of death. The justification for this is that all cause mortality is, after all, a more important indicator of health than the occurrence of single diseases. Moreover the allocation of causes of death becomes less and less accurate as age increases and more contemporary causes may interact in producing the fatal outcome.

One of the studies having the above characteristics is the Seven Countries Study on Cardiovascular Diseases, started in the late 1950s and conducted in 16 population samples of middle aged men in seven countries. ${ }^{16-20}$

Presently five cohorts in three countriesFinland, Italy and The Netherlands-have reached the 25 year anniversary follow up and data on mortality were collected over the whole period of time.

The purpose of this analysis is to describe the all cause mortality experience in 25 years and to correlate it with a number of cardiovascular risk factors measured at entry examination. This approach follows a similar analysis on coronary heart disease made recently on the same cohorts and for the same length of follow up. ${ }^{21}$

\section{Methods}

The five cohorts involved in this analysis are those called East Finland (EF) and West Finland (WF) in Finland, Zutphen (ZU) in The Netherlands, and Crevalcore (CR) and Montegiorgio (MO) in Italy, all made up of men aged $40-59$ years at entry examination.

The two Finnish cohorts included all men in the specified age range from geographically defined rural areas in North Karelia (EF) and in South West Finland (WF), drawn from the local register offices.

Zutphen is a small town in the centre east of The Netherlands where a statistical sample of $4 / 9$ of all the resident men in the specified age was enrolled.

Crevalcore and Montegiorgio are two small rural villages located in Northern and Central Italy respectively, where all men of the specified age range living or resident for at least five years were recruited. 
The entry examinations were held in 1959 in Finland, and in 1960 in The Netherlands and in Italy, with high participation rates $99.3 \%$ in EF; $97.0 \%$ in WF; $84.3 \%$ in ZU; $98.5 \%$ in CR; $99 \%$ in $\mathrm{MO}$ ).

For some purposes, pools of the areas in Finland (SF) and Italy (IT) have been used. In those analyses Zutphen alone represented The Netherlands (NL).

A number of measurements were taken as reported in detail elsewhere. ${ }^{161720}$ For the purpose of this analysis only the following, which were common to all five cohorts, were considered: age in years, rounded off at the nearest birthday (AGE); physical activity at work as estimated by a questionnaire $\quad(1=$ sedentary; 2 =moderate; 3 = heavy) (PHYAC); skinfold thickness in $\mathrm{mm}$, by adding the right triceps to the right subscapular skinfolds measured by a caliper (SKIN); body mass index in $\mathrm{kg}$ of weight $/ \mathrm{m}^{2}$ of height (BMI); serum cholesterol in $\mathrm{mg} / \mathrm{dl}$ measured in a casual blood sample by the method of Abel-Kendall as modified by Anderson and Keys (CHOL) ${ }^{22}$; the number of cigarettes smoked on average per day, as reported by the subjects (CIG); blood pressure in $\mathrm{mm} \mathrm{Hg}$ expressed as mean blood pressure (diastolic plus $1 / 3$ of systolic minus diastolic) (MBP)-measurements were taken in supine position at the end of a physical examination, in the right arm by trained physicians using standard mercury sphygmomanometers, following the technique described in the WHO manual Cardiovascular survey methods, ${ }^{23}$ and for both systolic and diastolic blood pressure the average of two consecutive measurements was used for analysis; heart rate in beats/min as measured on a resting electrocardiogram (HR); arm circumference in $\mathrm{mm}$, as measured at mid-point of right upper arm; the measurement was reduced to the contribution of bone and muscle using the triceps skinfold thickness as an estimate of skin plus subcutaneous tissue thickness (ARM); shoulder-pelvis shape, by dividing the biacromial by the bicristal diameter (in cm) (SPS); lateralitylinearity index, by the sum of the two above mentioned diameters divided by height in $\mathrm{cm}$, multiplied by 100 (LL); and trunk/height ratio, given by sitting height divided by standing height in $\mathrm{cm}$, multiplied by 100 (TH).

The collection of data on mortality and causes of death was complete for all men in the subsequent 25 years. In each area periodic site visits ascertained the fatal events through the local register office and then a large amount of medical information was collected through hospital records, interviews with physicians, relatives, officers, acquaintances, etc, in this way providing the necessary material to a single central reviewer for reaching a final diagnosis of cause of death following standard criteria. In Finland this was done only for the first 15 years of follow up, after which the cause of death was determined only by reviewing and coding copies of the death certificates.

Age standardised death rates were computed with the direct method using as reference population the quinquennial breakdown of the pool of all the Seven Countries cohorts.

The probability of death were estimated by the Cutler-Ederer life table technique. ${ }^{24}$
For the estimation of the predictive power of entry levels of risk factors on mortality the multiple logistic model was employed. ${ }^{25}$ The coefficients of the solutions on the national pools were then applied back to the original data (risk factors) in the same and different groups. The sum of the individually estimated probabilities was used as predicted number of events.

Another solution of the multiple logistic function was solved on the pool of all the cohorts and at the same time adding dummy variables for the identification of the nationality.

Finally a multiple linear regression model was also solved including the number of months lived after the entry examination as dependent variable, and the same 12 risk factors as predictors of the duration of survival.

\section{Results}

DEATH RATES AND LIFE EXPECTANCY

Table I gives the age adjusted death rates from all causes in 25 years in the five cohorts.

All cause mortality rates show large differences. The rate in East Finland is higher than any of the others $(p<0.001)$. Among the other possible comparisons, only West Finland and Montegiorgio differ significantly from each other $(p<0.05)$. When comparing the national pools it appears that death rates in Finland are higher than in Italy and in The Netherlands $(p<0.001)$. No significant differences were found between Italy and The Netherlands.

Table I Age adjusted death rates per 1000 in 25 years from all causes deaths. For the identification of symbols see Methods

\begin{tabular}{lcll}
\hline & & \multicolumn{2}{l}{ All cause mortality } \\
\cline { 3 - 4 } Cohort & $n$ & Rate & $S E$ \\
\hline EF & 817 & 604 & $16 \cdot 4$ \\
WF & 860 & 513 & $16 \cdot 4$ \\
ZU & 878 & 477 & $15 \cdot 9$ \\
CR & 993 & 488 & $15 \cdot 0$ \\
MO & 719 & 458 & $17 \cdot 2$ \\
EF + WF = SF & 1677 & 557 & $12 \cdot 1$ \\
CR + MO = IT & 1712 & 475 & $12 \cdot 1$ \\
\hline
\end{tabular}

Figure 1 gives the breakdown of the major causes of death within total mortality for each of the cohorts. Coronary heart disease seems to be the most variable condition among the six groups considered. A large proportion of total mortality differences is therefore explained by coronary heart disease mortality, which follows almost the same rank as total mortality. If coronary heart disease rates are subtracted from all cause rates, the differences between the five cohorts become decisively smaller, with residual non-coronary heart disease rates of 310 per 1000 in East Finland, 317 in West Finland, 282 in Zutphen, 359 in Crevalcore, and 345 in Montegiorgio. In this case, the rates of the two Italian cohorts are significantly higher than that in Zutphen; the rate in Crevalcore is statistically higher than those in the other cohorts except for Montegiorgio.

The rates of the Finnish and Italian pools of cohorts conform to the large coronary heart disease mortality differences between these two countries. 
Figure 1 Breakdown of all causes of death over 25 years into some specific causes for the five cohorts. For symbols see Methods

Figure 2 Survival probability computed by the Cutler-Ederer technique for the five cohorts. For symbols, see Methods
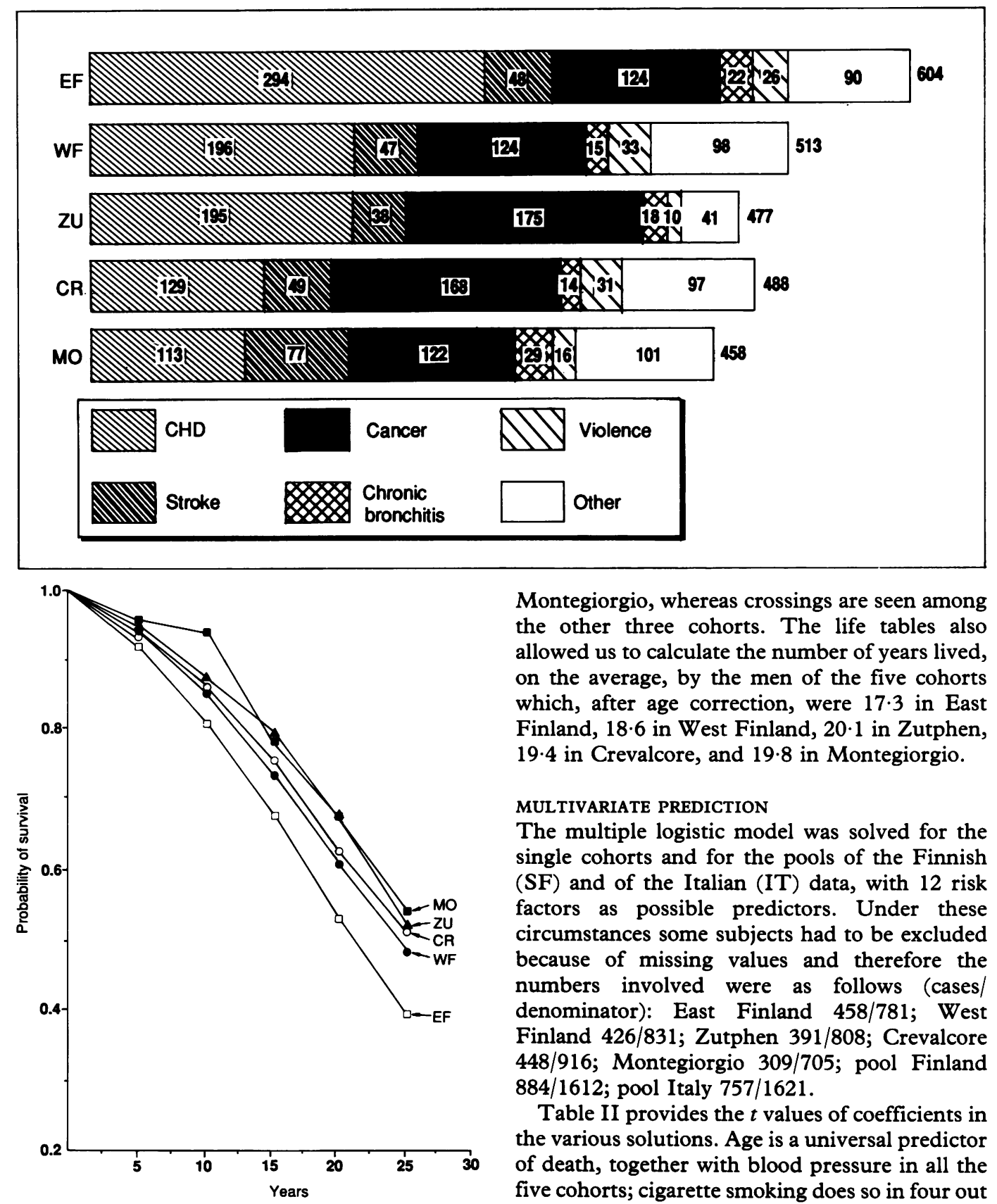

Another way to look at the differences between cohorts is to compute and plot the survival probabilities produced by the Cutler-Ederer technique $^{24}$ and given in fig 2 . There is no overlapping between East Finland and

Table II Solutions of the multiple logistic function for the five cohorts and their national pools, as a function of 12 risk factors, with all cause mortality as end point and 12 covariates. Data are $\mathrm{t}$ values of the coefficients. For the identification of symbols and units of measurement, see Methods

\begin{tabular}{|c|c|c|c|c|c|c|c|}
\hline & \multicolumn{7}{|l|}{ Cohort } \\
\hline & $E F$ & $W F$ & $Z U$ & $C R$ & MO & $S F$ & $I T$ \\
\hline $\begin{array}{l}\text { AGR } \\
\text { PHYAC } \\
\text { SKIN } \\
\text { BMI } \\
\text { CHOL } \\
\text { CIG } \\
\text { MBP } \\
\text { HR } \\
\text { ARM } \\
\text { SPS } \\
\text { LL } \\
\text { TH } \\
\text { CONSTANT }\end{array}$ & $\begin{array}{c}7.22^{\star} \\
0.05 \\
-0.71 \\
-0.13 \\
1.34 \\
5.35 \star \\
5.25 \star \\
-0.17 \\
-1.01 \\
-0.60 \\
1.55 \\
-0.71 \\
-2.41\end{array}$ & $\begin{array}{c}7.48^{\star} \\
-0.65 \\
-1 \cdot 12 \\
0.64 \\
-0.15 \\
4.40^{\star} \\
4.27^{\star} \\
1.91 \\
-1.81 \\
-1.49 \\
1.00 \\
-1.36 \\
-0.95\end{array}$ & $\begin{array}{c}9.29 \star \\
0.30 \\
-1.25 \\
1.50 \\
0.44 \\
1.54 \\
3.54^{\star} \\
1.60 \\
-2.52^{\star} \\
0.30 \\
-0.44 \\
-0.39 \\
-1.77\end{array}$ & $\begin{array}{c}9.02^{\star} \\
-0.03 \\
-1.33 \\
1.00 \\
2.45^{\star} \\
2.43^{\star} \\
4 \cdot 11^{\star} \\
2.53^{\star} \\
-2.31^{\star} \\
2.75^{\star} \\
0.35 \\
0.43 \\
-4.32\end{array}$ & $\begin{array}{c}8 \cdot 17^{\star} \\
-2 \cdot 66^{\star} \\
-2 \cdot 26^{\star} \\
2 \cdot 24^{\star} \\
0 \cdot 73^{\star} \\
3 \cdot 77^{\star} \\
4 \cdot 53^{\star} \\
-0.93 \\
-2 \cdot 82^{\star} \\
0 \cdot 26 \\
-0.12 \\
-0.28 \\
-1.78\end{array}$ & $\begin{array}{c}10.48^{\star} \\
-0.40 \\
-1.38 \\
0.43 \\
0.88 \\
6.89^{\star} \\
7.11^{\star} \\
1.36 \\
-2.09^{\star} \\
-1.57 \\
1.73 \\
-1.34 \\
-2.29\end{array}$ & $\begin{array}{r}12 \cdot 49^{\star} \\
-2.05^{\star} \\
-2.52^{\star} \\
1.98^{\star} \\
2 \cdot 63^{\star} \\
4.42^{\star} \\
6.05^{\star} \\
1.47 \\
-3.50^{\star} \\
2.45^{\star} \\
0.52 \\
0.33 \\
-5.38\end{array}$ \\
\hline
\end{tabular}

Montegiorgio, whereas crossings are seen among the other three cohorts. The life tables also allowed us to calculate the number of years lived, on the average, by the men of the five cohorts which, after age correction, were 17.3 in East Finland, 18.6 in West Finland, 20.1 in Zutphen, 19.4 in Crevalcore, and 19.8 in Montegiorgio.

\section{MULTIVARIATE PREDICTION}

The multiple logistic model was solved for the single cohorts and for the pools of the Finnish (SF) and of the Italian (IT) data, with 12 risk factors as possible predictors. Under these circumstances some subjects had to be excluded because of missing values and therefore the numbers involved were as follows (cases/ denominator): East Finland 458/781; West Finland 426/831; Zutphen 391/808; Crevalcore 448/916; Montegiorgio 309/705; pool Finland $884 / 1612$; pool Italy $757 / 1621$.

Table II provides the $t$ values of coefficients in the various solutions. Age is a universal predictor of death, together with blood pressure in all the five cohorts; cigarette smoking does so in four out of five cohorts (not Zutphen). The arm circumference is negatively related to the risk except in the two Finnish areas. Heart rate and shoulder/pelvis shape are significant only in Crevalcore. Body mass index (positive relationship) and skinfold thickness (negative relationship) are significant only in Montegiorgio, which is also the only cohort showing a significant (negative) coefficient of physical activity. By comparing the pools of Finland, Italy, and The Netherlands (represented by Zutphen) the significant factors are age, cigarettes, blood pressure, heart rate, arm circumference (negative) for Finland; the same plus blood cholesterol, body mass index, shoulder/pelvis shape (all positive) and physical activity, skinfold thickness, and arm circumference (all negative) in Italy; whereas in Zutphen only age, blood pressure, and arm circumference (negative) carry significant coefficients.

CROSS PREDICTION BETWEEN POPULATIONS

The coefficients of the national solutions have 
been applied back to the original data of each individual for each of the national pools. The observed cases were compared with the cases predicted by their own coefficients (self prediction), and with the cases predicted by the coefficients of the other two countries. This operation allows computation of the amount of overprediction or underprediction made by different sets of coefficients derived from different sources.

The numbers of cases actually observed and the numbers self predicted are rather close (table III), as usually happens when employing the multiple logistic function. The greatest error (in Italy) is of $-0.8 \%$.

In general the prediction of all cause deaths is good since the overestimates or underestimates are small. The smallest error concerns the prediction of the Italian events using the Dutch coefficients $(-2 \%)$, while the largest is that obtained by applying the Dutch coefficients to the Finnish experience $(+11 \cdot 2 \%)$.

The relative risks between different strata of estimated probabilities were rather similar when

Table III All cause mortality. Cases observed and cases predicted by applying back the coefficients of the multiple logistic solutions. In parenthesis the percentage of over $(+)$ or under (-) predicted cases, compared to the observed cases

\begin{tabular}{|c|c|c|c|c|}
\hline \multirow[b]{2}{*}{ Country } & \multicolumn{4}{|l|}{ Cases } \\
\hline & Observed & $\begin{array}{l}\text { Predicted } \\
\text { by } S F\end{array}$ & $\begin{array}{l}\text { Predicted } \\
\text { by NL }\end{array}$ & $\begin{array}{l}\text { Predicted } \\
\text { by } I T\end{array}$ \\
\hline $\begin{array}{l}\text { SF } \\
\text { NL } \\
\text { IT }\end{array}$ & $\begin{array}{l}884 \\
391 \\
757\end{array}$ & $\begin{array}{l}879(-0 \cdot 6) \\
435(+11 \cdot 2) \\
812(+7 \cdot 3)\end{array}$ & $\begin{array}{l}824(-6 \cdot 8) \\
390(-0 \cdot 3) \\
742(-2 \cdot 0)\end{array}$ & $\begin{array}{l}835(-5 \cdot 6) \\
406(+3 \cdot 8) \\
751(-0 \cdot 8)\end{array}$ \\
\hline
\end{tabular}

$\mathrm{SF}=$ Finland, $\mathrm{NL}=\mathrm{The}$ Netherlands, $\mathrm{IT}=$ Italy

Table IV Some indicators of discrimination when applying back the multiple logistic coefficients to the original data and comparing the observed cases in decile or quintile classes of estimated risk. 10th decile $\%=$ proportion of observed cases in the top decile of the estimated probabilities; 5th quintile $\%=$ proportion of the observed cases in the top quintile of the estimated probabilities;

$R R 10 / 1=$ Relative risk of top decile on bottom decile; $R R 5 / 1=$ Relative risk of top quintile on bottom quintile

\begin{tabular}{|c|c|c|c|c|c|}
\hline $\begin{array}{l}\text { Coefficients } \\
\text { of }\end{array}$ & On data of & $\begin{array}{l}\text { 10th Decile } \\
\%\end{array}$ & $\begin{array}{l}\text { 5th Quintile } \\
\%\end{array}$ & $R R \quad 10 / 1$ & $R R 5 / 1$ \\
\hline $\begin{array}{l}\text { SF } \\
\text { NL } \\
\text { IT } \\
\text { NL } \\
\text { SF } \\
\text { IT } \\
\text { IT } \\
\text { SF } \\
\text { NL }\end{array}$ & $\begin{array}{l}\text { SF } \\
\text { SF } \\
\text { SF } \\
\text { NL } \\
\text { NL } \\
\text { NL } \\
\text { IT } \\
\text { IT } \\
\text { IT }\end{array}$ & $\begin{array}{l}16.1 \\
15.7 \\
15.6 \\
16.6 \\
15.9 \\
17.1 \\
18.9 \\
18.5 \\
18.5\end{array}$ & $\begin{array}{l}30.3 \\
29.9 \\
29 \cdot 6 \\
32 \cdot 2 \\
29.4 \\
30 \cdot 7 \\
34.9 \\
33.9 \\
34.3\end{array}$ & $\begin{array}{l}4 \cdot 2 \\
3.6 \\
3.5 \\
5.9 \\
3 \cdot 6 \\
4 \cdot 2 \\
5 \cdot 3 \\
4.8 \\
5.4\end{array}$ & $\begin{array}{l}3 \cdot 1 \\
2 \cdot 8 \\
3.0 \\
4 \cdot 2 \\
2.9 \\
2.9 \\
4 \cdot 2 \\
3.7 \\
3.9\end{array}$ \\
\hline
\end{tabular}

SF $=$ Finland, $\mathrm{NL}=$ The Netherlands, $\mathrm{IT}=$ Italy

Table $V$ Solution of the multiple logistic function for all cause deaths in 25 years (2025 events in 4027 men) as a function of 12 risk factors in the pool of the five cohorts in three countries, including dummy variables for the identification of nationality. For units of measurement see text

\begin{tabular}{|c|c|c|c|}
\hline Factor & $\begin{array}{l}\text { Average value } \\
\text { of factor }\end{array}$ & Coefficient & t value \\
\hline $\begin{array}{l}\text { Age } \\
\text { Physical activity } \\
\text { Skinfold thickness } \\
\text { Body mass index } \\
\text { Cholesterol } \\
\text { Cigarettes } \\
\text { Mean blood pressure } \\
\text { Heart rate } \\
\text { Arm circumference } \\
\text { Shoulder-pelvis shape } \\
\text { Laterality-linearity index } \\
\text { Trunk-height ratio } \\
\text { Dummy Italy } \\
\text { Dummy Netherlands } \\
\text { Dummy Finland } \\
\text { Constant }\end{array}$ & $\begin{array}{r}49 \cdot 72 \\
2 \cdot 47 \\
20 \cdot 68 \\
24 \cdot 27 \\
232 \cdot 25 \\
9 \cdot 71 \\
105 \cdot 38 \\
69 \cdot 97 \\
26 \cdot 29 \\
134 \cdot 42 \\
40 \cdot 26 \\
53 \cdot 05 \\
= \\
=\end{array}$ & $\begin{array}{r}0.1348 \\
-0.0930 \\
-0.0203 \\
0.0474 \\
0.0019 \\
0.0291 \\
0.0287 \\
0.0079 \\
-0 \cdot 1097 \\
0.0021 \\
0.0318 \\
-0.0142 \\
-0.0809 \\
-0.1232 \\
\text { Reference } \\
-9.4918\end{array}$ & $\begin{array}{l}18 \cdot 87^{\star} \\
-1 \cdot 59 \\
-3 \cdot 22^{\star} \\
2 \cdot 00^{\star} \\
2 \cdot 52^{\star} \\
8 \cdot 02^{\star} \\
9 \cdot 86^{\star} \\
2 \cdot 75^{\star} \\
-4 \cdot 57^{\star} \\
0 \cdot 45 \\
1 \cdot 35 \\
-0 \cdot 58 \\
-1 \cdot 66 \\
-2 \cdot 07^{\star} \\
-\end{array}$ \\
\hline
\end{tabular}

$\star \mathrm{p}<0.05$ using the coefficients of the same country or the coefficients of another country. Table IV summarises some of such estimates based on the distribution of the observed cases in decile classes of the estimated risk. The proportion of observed cases located in the 10th decile of the distribution ranged from $15.6 \%$ to $18.9 \%$; the proportion of observed cases in the 5 th quintile of the distribution ranged from $29.6 \%$ to $34.9 \%$; the relative risk of 10 th decile/ 1 st decile of the distribution was between 3.6 and 5.9; and that of 5 th quintile/ 1 st quintile between $2 \cdot 8$ and $4 \cdot 2$. The discrimination obtained by the use of the coefficients of the same country was a little better than that obtained by the use of coefficients of other countries. In general all the computations made on the Italian data showed a better discrimination.

MULTIVARIATE ANALYSIS IN POOLED POPULATIONS Another analysis to explain the intercountry differences of mortality was made by computing another solution of the logistic model, with the same factors as predictors, on the pool of the five cohorts combined. In this case, dummy variables were added for the identification of nationality and the Finnish men were taken as reference $(0-0)$, the Dutch men were identified by $1-0$, and the Italians by $0-1$. The solution is shown in table V. It provides the "average coefficients" for the three national groups, and the dummy variables give the information on the contribution to prediction of such special characteristics of the single nations which are not included among the risk factors considered. The factors now carrying significant coefficients are age, body mass index, serum cholesterol, cigarette smoking, blood pressure, heart rate, arm circumference (negative), and skinfold thickness (negative), while the two dummy variables provide negative coefficients (significant for The Netherlands). This means that, everything else being equal, the risk for Italian and Dutch men is lower than for Finnish men, reflecting the different nationalities. To show this, the coefficients of the solution were applied back to the "average man" as characterised by the mean levels of all the factors for all the countries pooled. When all the other determinants were kept fixed and the nationality specified in terms of dummy variables, the risk of death was 0.4844 for an average Finnish man, 0.4537 for a similar Dutch man, and 0.4642 for a similar Italian man. The relative risk Finn/Dutch was 1.07 and that of Finn/Italian was 1.04.

MULTIVARIATE PREDICTION OF MONTHS LIVED

The solutions of the multiple linear regression, using as end point the months lived by each man after the entry examination for a maximum of 300 months (25 years), are given in table VI. Age provides significant coefficients as well as mean blood pressure. Serum cholesterol, shoulderpelvis shape, and trunk-height ratio are significant in none of the solutions. The other factors are significant in some of them, ie, physical activity in five out of seven solutions; skinfold thickness in four; body mass index in three; heart rate in two; laterality-linearity index in two; cigarette smoking in five; arm circumference in five. All the algebraic signs are inverse as 
Table VI Solution of the multiple linear regression for the five cohorts and their national pools predicting the number of months lived after entry examination as a function of 12 risk factors. Data are $\mathrm{t}$ values of the coefficients. For identification of symbols and units of measurements, see Methods

\begin{tabular}{|c|c|c|c|c|c|c|c|}
\hline & $E F$ & $W F$ & $Z U$ & $C R$ & $M O$ & $S F$ & $I T$ \\
\hline AGE & $-7 \cdot 33^{\star}$ & $-6 \cdot 43^{\star}$ & $-7 \cdot 82^{\star}$ & $-7 \cdot 59^{\star}$ & $-6 \cdot 84^{\star}$ & $-9 \cdot 94^{\star}$ & $-10.49^{\star}$ \\
\hline PHYAC & $3 \cdot 23^{\star}$ & $2 \cdot 14^{\star}$ & $0 \cdot 27$ & 0.76 & $2 \cdot 83^{\star}$ & $3 \cdot 72^{\star}$ & $2 \cdot 41^{\star}$ \\
\hline SKIN & 1.81 & 1.63 & 0.35 & $2 \cdot 81^{\star}$ 太 & $2 \cdot 38^{\star}$ & $2 \cdot 44^{\star}$ & $3 \cdot 80^{\star}$ \\
\hline BMI & 0.35 & -0.97 & -0.42 & $-2 \cdot 20^{\star}$ & -1.72 & -0.44 & $-2 \cdot 70^{\star}$ \\
\hline CHOL & -1.63 & $1 \cdot 10$ & -0.77 & -0.88 & -0.52 & -0.50 & -1.09 \\
\hline CIG & $-3 \cdot 56^{\star}$ & $-4 \cdot 83^{\star}$ & -0.88 & -1.93 & $-2 \cdot 76^{\star}$ & $-5 \cdot 49^{\star}$ & $-3 \cdot 31^{\star}$ \\
\hline MBP & $-6 \cdot 70^{\star}$ & $-4 \cdot 86^{\star}$ & $-4 \cdot 39^{\star}$ & $-6 \cdot 98^{\star}$ & $-4 \cdot 62^{\star}$ & $-8 \cdot 24^{\star}$ & $-8 \cdot 60^{\star}$ \\
\hline HR & $-1 \cdot 30$ & $-2 \cdot 71^{\star}$ & -1.06 & -1.84 & -0.40 & $-3 \cdot 15^{\star}$ & $-1 \cdot 72$ \\
\hline ARM & 0.85 & $3 \cdot 20^{\star}$ & 1.82 & $4 \cdot 01^{\star}$ & $3 \cdot 79^{\star}$ & $2 \cdot 95^{\star}$ & $5.51^{\star}$ \\
\hline SPS & -0.73 & $3 \cdot 25^{\star}$ & 1.56 & $-2 \cdot 13^{\star}$ & 0.42 & 1.79 & -1.52 \\
\hline LI & $-2 \cdot 20^{\star}$ & -0.87 & -0.68 & -0.37 & -0.22 & $-2 \cdot 04^{\star}$ & -0.46 \\
\hline TH & -0.33 & 1.00 & 0.79 & $-1 \cdot 17$ & 1.35 & 0.70 & $-0 \cdot 16$ \\
\hline CONST & $787 \cdot 18$ & $211 \cdot 36$ & $381 \cdot 66$ & 752.03 & $241 \cdot 65$ & 457.75 & $563 \cdot 71$ \\
\hline
\end{tabular}

compared to those of the solutions of the multiple logistic equation since the end point was survival instead of mortality.

PREDICTABILITY FOR DIFFERENT LENGTH OF FOLLOW UP

During the conduction of the analysis the question was raised as to whether the predictive value of the available factors might be different if shorter or different periods of follow up were selected. Table VII summarises, in a semiquantitative way, the predictive power of the 12 factors in the three national pools for the estimation of the events occurring in the first 10 years, in the second 15 years, and in the whole 25 years, always as a function of the entry levels of risk factors. It appears that only age and blood pressure give the same response, over the different periods considered, in all three countries, though it applies for cigarette consumption in Finland and for arm circumference in Italy. In The Netherlands no other factor is ever significant except arm circumference over the whole 25 years; in Finland four other factors are predictive only in the first 10 year follow up, whereas in Italy many factors are predictive, at least in the late stages of the follow up.

Table VII Multiple logistic functions solved for the prediction of all causes of death in the pools of cohorts of three countries. Significant factors for the prediction of events for the first 10 years (10) for the second years (10) for the second
15 years (15) and for the whole 25 years period (25). For explanation of symbols, see Methods

\begin{tabular}{llcc}
\hline & $S F$ & $N L$ & $I T$ \\
\hline AGE & $10-15-25$ & $10-15-25$ & $10-15-25$ \\
PHYAC & 10 & - & $10-25$ \\
SKIN & - & - & 25 \\
BMI & $\bar{Z}$ & - & $15-25$ \\
CHOL & $10-15-25$ & - & 25 \\
CIG & $10-15-25$ & $10-15-25$ & $10-15-25$ \\
MBP & 10 & - & 15 \\
HR & $10-$ & - & $10-15-25$ \\
ARM & 10 & - & -25 \\
SPS & 10 & - & - \\
LI & 10 &
\end{tabular}

\section{Discussion}

The 25 year follow up of these five cohorts in three European countries confirms the existence of some differences in all cause mortality rates, which are relevant at least between the Finnish and one of the Italian cohorts. This is also reflected by the picture given by the life tables and by the average number of years lived from the enrolment and the end of the follow up. They are similar, in hierarchical terms, to those already observed in shorter periods of follow up 2161720 but they provide more credibility due to the larger numbers of events. However, almost all the differences in total mortality are explained by the coronary component. As a consequence the noncoronary mortality rates are slightly higher in the two Italian cohorts, which in turn exhibit the lowest coronary burden. This implies that at least in the two Finnish cohorts, which are characterised by the highest levels of the major coronary risk factors, there are competing risks between coronary events on the one hand and other causes of death on the other. This problem will be tackled by appropriate analysis at another occasion.

The individual prediction of all cause mortality was attempted by the use of the multiple logistic function. ${ }^{25}$ The ideal model for observations characterised by such a long period of follow up would have been the Cox model. ${ }^{26-28}$ However, after several attempts it was concluded that the assumption of proportionality was violated, at least for serum cholesterol in the Finnish cohorts and for cigarette consumption in Zutphen. The multiple logistic model was therefore preferred, although it does not take into consideration the timing of the fatal events and the changing denominators.

As an exploratory alternative the multiple linear regression model was solved, as shown in table VI, using as dependent variable the number of months lived by each man after the entry examination. The net result was that, apart from the change of algebraic signs, more or less the same factors were significant in the multiple logistic model and in the multiple regression model. Incidentally, the results preliminarily obtained by the use of the Cox model were also, apart from the violation of the proportionality assumption, substantially the same.

In any case the multiple logistic solutions in the single cohorts or in pools of national cohorts has confirmed the universal predictive role of age, blood pressure, and smoking habits. ${ }^{124910-15172029}$ However for the latter characteristics this is not true in the Dutch cohort. The failure of smoking habits to provide significant coefficients in Zutphen could be attributed to the existence of a large proportion of cigar and pipe smokers and of mixed smokers (cigarette + cigar or pipe) for whom a correct estimate of the amount of tobacco smoked per day was not possible in this analysis. Moreover the large majority of the smokers were moderate with daily consumption of 10-19 cigarettes.

All the other factors appear only sporadically as important predictors of all cause mortality, but more commonly in the two Italian cohorts than in the others. On the other hand arm circumference was inversely related to all causes of death in Zutphen, the two Italian cohorts, the Italian pool, and the Finnish pool. Arm circumference, after subtraction of the contribution of skin and subcutaneous tissues, can be regarded as an indicator of muscular mass and thus one facet of physical fitness. It is also moderately correlated with the physical activity rating. The other anthropometric measurements do not play any important role in predicting all cause mortality.

In general the universality of some factors, such as those identified in this paper, is largely recognised by those few studies which have shown an interest in all cause mortality. ${ }^{891213152129}$ 
The Seven Countries Study has a long tradition of attempting the estimation of events in a given population employing the risk function of other population groups, that is, the true prediction. The experience with data of 5, 10 and 15 year follow up usually produced, for the prediction of coronary events, overestimation or underestimation of cases, depending on the direction of the comparison. ${ }^{171820}$ In particular, northern European and North American solutions largely overestimated mortality and incidence in southern European cohorts and vice versa. Only in a report concerning 15 year follow up was cross prediction attempted for all cause mortality. ${ }^{20}$ In that study solutions from northern European cohorts overestimated all cause mortality in southern Europe by $10 \%$, whereas with the inverse procedure the underestimation was $15 \%$

In this analysis the overall results follow traditional lines but the disagreements are rather limited. The errors in estimating events for all cause mortality are contained within limits which only once exceed $\pm 10 \%$. Considering the geographical, cultural, and ethnic differences, and the limited number and typology of the available factors, this is acceptable. This means that at least in the conditions of this analysis a true prediction of total mortality is feasible.

The discrimination between cases and noncases, as suggested by the distribution of observed cases in decile or quintile classes of the estimated risk, is good although not much is shown for shorter periods of follow up and mainly for more specific end points. ${ }^{17} 1820$ It is likely that many other factors need to be investigated for more powerful discrimination. Such limited errors in predicting the events are also reflected by the analysis which included the dummy variables identifying the single nationalities.

The analysis concerning the predictive power of the considered factors for shorter or different periods of follow up tends to reinforce the basic role of age and blood pressure, and partly of smoking habits and arm circumference, whereas the other factors are of relevance only in some areas or for some time periods. It is clear that a proper analysis, from this point of view, should include an estimate of changing levels of risk factors and their impact on prediction. This approach will be followed in due course.

At this stage of follow up the real problem seems to be the need for a better understanding of the competing risks bound to the differences in risk factor means and distribution, to the dynamics of risk factors, and to the effect of these components on specific and overall causes of death.

Research partly developed within the subproject "Community Medicine" of the targeted project FATMA (Risk Factors and Disease Control) of the CNR (Italian National Research Council). Contract N 9100289 PF41 to A Menotti.

1 Shurtleff D. Some characteristics related to incidence of cardiovascular disease and death: Framingham Study, 18 year follow-up. In: Kannel WB, Gordon T, eds. The Framingham Study. An epidemiological investigation of
cardiovascular disease, Section 30 . Bethesda, MD: DHEW Publication (NIH) N.74-599, 1974.
2 Menotti A, Keys A, Aravanis C, et al. Seven Countries Study. First 20 -year mortality data in 12 cohorts of six countries. Ann Med 1989; 21: 175-9.

3 Menotti A, Keys A, Nissinen A, Kromhout D, Seccareccia F. The Seven Countries Study. 25 year experience in three countries. In: Muntoni S, Epstein FM, Lamm G, eds. Epidemiology of atherosclerosis. Rome: CIC Edizioni Internazionali, 1988: 19-25.

4 Kannel WB. Framingham Study 30 year follow-up: current status of cardiovascular risk factors. In: Muntoni S, Epstein FM, Lamm G, eds. Epidemiology of atherosclerosis. Rome CIC Edizioni Internazionali, 1988, 27-31.

5 Kaplan GA, Seeman TE, Cohen RD, Knudsen LP, Guzalnik J. Mortality among the elderly in the Alameda County Study. Behavioural and demographic risk factors. Am 7 Public Health 1987; 77: 307-12.

6 Tyroler HA, Hames CG, Gazes PL, Keil JE. Cardiovascular disease epidemiology of blacks in the Evans County and Charleston heart studies. In: Muntoni S, Epstein FH, Lamm G, eds. Epidemiology of atherosclerosis. Rome: CIC Edizioni Internazionali, 1988; 33-41.

7 Karvonen MJ, Aromaa A, Salonen J, Tuomilehto J. The Finnish cohort studies. In: Muntoni S, Epstein FM, Lamm G, eds. Epidemiology of atherosclerosis. Rome: CIC Edizioni Internazionali, $1988 ; 15-18$.

8 Keys A. Longevity of man. Relative weight and fatness in middle age. In: Muntoni S, Epstein FM, Lamm G, eds. Epidemiology of atherosclerosis. Rome: CIC Edizion Internazionali, 1988; 3-13.

9 Keys A, Taylor HL, Blackburn H, Brozek J, Anderson JT, Simonson E. Mortality and coronary heart disease among men studied for twenty-three years. Arch Intern Med 1971; men studied for

10 Menotti A, Mariotti S, Seccareccia F, Torsello S, Dima F. Determinants of all causes of death in Italian middle-aged men followed up for 25 years. 7 Epidemiol Community Health 1987; 41: 243-50.

11 Menotti A, Conti S, Dima F, et al. Prediction of all causes of death as a function of some factors commonly measured in cardiovascular population survey. Prev Med 1983; 12: 318-25.

12 Dyer AR, Stamler J, Berkson DM, Lindberg HA. Relationship of relative weight and body mass index to 14 year mortality in the Chicago people Gas Company study. $\mathcal{F}$ Chron Dis 1975; 28: 109-23.

13 Menotti A, Seccareccia F. Cardiovascular risk factors predicting all causes of death in an occupational population sample. Int $\mathcal{F}$ Epidemiol 1988; 17: 773-8.

14 Bonfante R, Reed D, Brody J. Biological and social predictors of health in an aging cohort. $\mathcal{F}$ Chron Dis 1985 38: 385-95.

15 Raynor WJ, Shekelle RB, Rossof AH, Maliza C, Paul O. High blood pressure and 17 year mortality in the Western Electric Health Study. Am f Epidemiol 1981; 113: 371-7.

16 Keys A, Aravanis C, Blackburn H, et al, eds. Coronary heart disease in Seven Countries. Circulation 1970; 41: (suppl 1): $1-211$

17 Keys A, Aravanis C, Blackburn H, et al. Seven Countries Study. A multivariate analysis of death and coronary hear disease. Cambridge, MA, USA: Harvard University Press, 1980: 1-381.

18 Keys A, Aravanis C, Blackburn H, et al. Probability of middle-aged men developing coronary heart disease in five years. Circulation 1972; 45: 815-28.

19 Keys A, Aravanis C, Blackburn H, et al. The diet and all causes death rates in the Seven Countries Study. Lance 1981; ii: $58-61$.

20 Keys A, Menotti A, Aravanis C, et al. The Seven Countries Study. 2289 deaths in 15 years. Prev Med 1984; 13: 141-54.

21 Menotti A, Keys A, Kromhout D, et al. Twenty-five year mortality from coronary heart disease and its prediction in five cohorts of middle aged men in Finland, The Netherlands and Italy. Prev Med 1990; 19: 270-8.

22 Anderson JT, Keys A. Cholesterol in serum and lipoprotein fractions: its measurement and stability. Clin Chem 1986; 2 145-59.

23 Rose G, Blackburn H. Cardiovascular survey methods. Geneva: WHO, 1968.

24 Cutler SJ, Ederer F. Maximum utilization of life table method in analysing survival. $\mathcal{f}$ Chron Dis $1958 ; 8: 699-712$

25 Walker S, Duncan DB. Estimation of the probability of an event as a function of several independent variables. Biometrika 1967; 54: 167-9.

26 Cox DR. Regression models and life tables. $\mathcal{F} R$ Stat Soc 1972; B34: 187-220.

27 Woodbury MA, Manton KG, Stallard E. Longitudinal models for chronic disease risk: an evaluation of logistic multiple regression and alternatives. Int $\mathcal{f}$ Epidemiol 1981; 10: 187-97.

28 Green MS, Symons MJ. A comparison of the logistic risk function and the proportional hazards model in prospective epidemiologic studies. $f$ Chron Dis 1983; 36: 715-24.

29 Kannel WB, Neaton JD, Wentworth D, et al. Overall and coronary heart disease mortality rates in relation to major risk factors on 325,348 men screened for the MRFIT. Am Heart $\mathcal{F} 1986$; 112: 825-36. 